\title{
Spectrophotometric Determination and Thermodynamic Parameters of Charge Transfer Complexation Between Stavudine and Chloranilic Acid
}

\author{
Wilfred O Obonga, Edwin O Omeje ${ }^{\star}$, Philip F Uzor and Malachy O Ugwu \\ Department of Pharmaceutical and Medicinal Chemistry, Faculty of Pharmaceutical Sciences, University of Nigeria, \\ 41000, Nsukka, Nigeria
}

\begin{abstract}
Purpose: The official assay methods for most antiretroviral drugs are limited by cost and unavailability of good test equipment in several developing countries. Therefore, this study investigates the use of charge transfer complexation in the spectrophotometric assay of stavudine as an alternative method to conventional methods.

Methods: Charge transfer complex formation between stavudine (n-donor) and chloranilic acid ( $\pi$ acceptor) in 1,4-dioxan using a spectrophotometer was employed. Thermodynamic parameters of the complex formed were determined. The proposed method was employed in the analysis of commercially available stavudine dosage form.

Results: The wavelength of maximum absorption $\left(\lambda_{\max }\right)$ of the complex was at $526 \mathrm{~nm}$ compared to 457 $\mathrm{nm}$ for $\pi$-acceptor alone. Beer's law was obeyed in the range of $5-40 \mathrm{mg} \%$ while the stoichiometry of the complex was found to be $2: 1$. The complex formed was still stable $24 \mathrm{~h}$ later. Its formation was spontaneous with a $\Delta \mathrm{H}^{\circ}$ of $-3.78 \times 10^{3} \mathrm{~J} / \mathrm{mol}$. The standard entropy change was from $12.18 \pm 0.78$ to $11.08 \pm 1.23 \mathrm{cal} / \mathrm{deg} / \mathrm{mol}$ over the temperature range of $30-60^{\circ} \mathrm{C}$ while molar absorptivity decreased from $2.45 \times 10^{5}$ to $1.2 \times 10^{5}$ over the same temperature range. The assay result of the standard stavudine solution was of high accuracy with a recovery value of $99.85 \pm 1.95 \%$.

Conclusion: The proposed method is reliable and reproducible and should be suitable for the quality control of stavudine in bulk and dosage forms.
\end{abstract}

Keywords: Assay, Charge transfer, Stavudine, Spectrophotometric analysis, Chloranilic acid, Thermodynamic. 


\section{INTRODUCTION}

Molecular interactions between electron donors and electron acceptors are generally associated with the formation of intensely colored charge-transfer complexes, which absorb radiation in the visible region [1]. Charge transfer complexes are formed between electron donors having sufficiently low ionization potential, and electron acceptors having sufficiently high electron affinity. The transfer of an electron from a donor to an acceptor is readily possible in the charge transfer process [2]. Chloranilic acid and a variety of other electron-accepting compounds have been reported to yield charge-transfer complexes leading to their utility in the development of simple and convenient spectrophotometric methods for the analysis of many drugs [3-8]. Such a complexation reaction is usually simple, fast, reproducible and reliable.

Stavudine is a synthetic thymidine nucleoside analogue active against human immunodeficiency virus [9]. It contains in its molecular structure, basic centers with the availability of non-bonding electrons as donors. Stavudine has the structural formula presented in Fig. 1a while the structure of chloranilic acid is shown in Fig. $1 \mathrm{~b}$. (a)<smiles></smiles><smiles>O=C1C(O)=C(Cl)C(=O)C(O)=C1Cl</smiles>

Figure 1: Structure of (a) stavudine and (b) chloranilic acid

High performance liquid chromatography (HPLC), thin layer chromatography, polarography, ultraviolet (UV) and infra-red (IR) spectrophotometry have been reported for the assay of stavudine [10]. Some of these techniques require complex procedure and instrumentation. For instance, HPLC methods generally require complex and expensive equipment, provision for use and disposal of solvents, labor-intensive sample preparation procedure and skilled personnel in chromatographic techniques [11]. Thus, the purpose of this study was to find a simple, rapid and reproducible method for the assay of stavudine which is an important drug in the treatment of HIV infection.

\section{EXPERIMENTAL}

\section{Materials}

The following materials were procured from local suppliers: two commercial stavudine capsule products - one (unbranded) from Strides Arcolab, India (40 mg/tab) and the other, Melxicap ${ }^{\circledR} \quad(40 \mathrm{mg} /$ tablet, Evans Medical Plc, Lagos, Nigeria). The pure sample of stavudine was a gift from Arcolab through the Federal Medical Center, Abakaliki, Nigeria. Other materials used were 1,4-dioxan (BDH, UK), methanol (Scharlau Chemie, S.A., Spain). All other reagents and solvents were of analytical grade and used as received. All laboratory reagents were freshly prepared.

\section{Preparation of standard solutions}

\section{Chloranilic acid}

A stock solution of chloranilic acid $\left(3.5 \times 10^{-3}\right.$ $\mathrm{M})$ was prepared by dissolving $0.073 \mathrm{~g}$ of chloranilic acid powder, accurately weighed, in 1, 4-dioxan and making up to $100 \mathrm{ml}$ with the same solvent. Further dilutions were carried out using 1, 4-dioxan to obtain lower concentrations.

\section{Stavudine}

A standard stock solution of stavudine in methanol was prepared by dissolving $1.26 \mathrm{~g}$ of stavudine powder in methanol in a $100 \mathrm{ml}$ volumetric flask and made up to volume with the same solvent to provide a $5.6 \times 10^{-2} \mathrm{M}$ solution. Further dilutions were carried out using methanol to obtain lower concentrations. 


\section{Absorption spectrum of chloranilic acid}

Chloranilic acid $(2 \mathrm{ml})$ stock solution was scanned in a spectrophotometer (UNICO 2102 PC, USA) in the wavelength range of $400-700 \mathrm{~nm}$ to determine its wavelength of maximum absorption.

\section{Absorption spectrum of stavudine-chloranilic acid complex}

Chloranilic acid $(2 \mathrm{ml})$ stock solution $\left(3.5 \times 10^{-3}\right.$ M) was mixed with $2 \mathrm{ml}$ of stavudine $\left(5.6 \times 10^{-}\right.$ $\left.{ }^{2} \mathrm{M}\right)$ solution. The contents were mixed and left at room temperature for $1 \mathrm{~h}$. A colour was developed and the complex formed was scanned spectrophotometrically against the blank of dioxan and methanol in the wavelength range of $400-700 \mathrm{~nm}$.

Beer's calibration plot for the stavudinechloranilic acid complex

Serial volumes (ranging from 0.4 to $2.8 \mathrm{ml}$ ) of the stock stavudine solution $\left(5.6 \times 10^{-2} \mathrm{M}\right)$ in $0.4 \mathrm{ml}$ steps were transferred to different test tubes. Sufficient volumes of methanol were added to bring the volume in each test tube to $3 \mathrm{ml} ; 2 \mathrm{ml}$ of chloranilic acid $\left(3.5 \times 10^{-3} \mathrm{M}\right)$ was added to each of the test tubes to afford a final concentration range of $2.24 \times 10^{-2} \mathrm{M}$ $1.56 \times 10^{-1} \mathrm{M}$. The contents were mixed and left at room temperature for $1 \mathrm{~h}$. The absorbance of each sample was determined at the wavelength of maximum absorption $\left(\lambda_{\max }\right.$ of $\left.526 \mathrm{~nm}\right)$ against blank of 1, 4-dioxan $(2 \mathrm{ml})$ and methanol $(3 \mathrm{ml})$.

\section{Time - absorbance relationship}

A time - absorbance relationship was established for the complex to determine the time the complex will take to develop fully. Equal volumes $(2 \mathrm{ml})$ and equimolar concentrations $\left(5.0 \times 10^{-3} \mathrm{M}\right)$ of the drug and chloranilic acid were mixed and absorbance taken at various time intervals from 0 to $18 \mathrm{~min}$ at $526 \mathrm{~nm}$.

\section{Determination of stoichiometry of the complex}

Job's method of continuous variation was employed [12]. Equimolar concentrations $\left(3.0 \times 10^{-2} \mathrm{M}\right)$ of solutions of stavudine and chloranilic acid were used for the experiment. A series of $5 \mathrm{ml}$ volumes of mixtures of the above solutions comprising complementary proportions of the two solutions in various ratios ranging from $0.5: 4.5$ to $4.5: 0.5$ (chloranilic acid: stavudine solution) were transferred into different test tubes and the complex formed for each reaction mixture was allowed to stand for $1 \mathrm{~h}$ at room temperature before analysis at $526 \mathrm{~nm}$. A blank solution consisting of chloranilic acid ( 2 $\mathrm{ml})$ and methanol ( $3 \mathrm{ml}$ ) was used.

\section{Determination of stability constant, molar absorptivity and thermodynamic parameters}

Serial volumes of $3.0 \times 10^{-2} \mathrm{M}$ solution of stavudine ranging from 0.4 to $2.8 \mathrm{ml}$, in 0.4 $\mathrm{ml}$ steps, were transferred to different test tubes. The solutions were diluted to $3 \mathrm{ml}$ with methanol and $1 \mathrm{~mL}$ of a $3.0 \times 10^{-2} \mathrm{M}$ solution of chloranilic acid in 1, 4-dioxan was added to each test tube. The contents were capped and mixed by gentle shaking. The test tubes were allowed to stand for $1 \mathrm{~h}$ at room temperature $\left(30{ }^{\circ} \mathrm{C}\right)$, and absorbance measurements were taken spectrophotometrically at $526 \mathrm{~nm}$ against a blank of methanol and dioxan. Further analyses of the reaction mixtures were carried out at temperatures of 40,50 and 60 ${ }^{\circ} \mathrm{C}$, respectively. The molar absorptivity, thermodynamic parameters and association constant for the stavudine-chloranilic acid complex were evaluated using the BenesiHildebrand equation (Eq 1) [13] and the data are shown in Table 1.

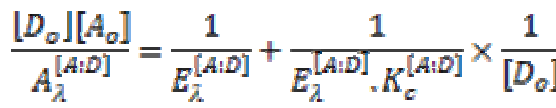

where $\left[D_{0}\right]$ and $\left[A_{0}\right]_{\text {are initial concentrations }}$ of the reactants, $A_{\lambda}{ }^{[A: D]}$ is the absorbance of 
the complex at $526 \mathrm{~nm}, \mathrm{E}_{\lambda}^{[A: D]}$ is the molar absorptivity of the complex at $526 \mathrm{~nm}$, and $\mathrm{K}_{\mathrm{c}}^{[\mathrm{A}: \mathrm{D}}$ is the stability constant. The regression equations for the plots at the temperatures of $30,40,40$ and $60^{\circ} \mathrm{C}$ were found as follows, $Y=0.7264 x+0.9307\left(R^{2}=0.9854\right), 0.6064 x+$ $1.0713\left(R^{2}=0.963\right), \quad 0.5826 x+0.989$ $\left(R^{2}=0.9599\right), \quad 0.5407 x+0.934 \quad\left(R^{2}=0.9477\right)$ respectively. The $R^{2}$ values, which were all above 0.9 , indicate very good correlations suggesting dependable data from the experiment. The intercepts and slopes of the regression lines from a plot of $\left[D_{0}\right]\left[A_{0}\right] / A_{\lambda}{ }^{[A: D]}$ against $1 /\left[D_{0}\right]$ were used to calculate the values of $E_{\lambda}[A: D]$ and $K_{c}^{[A: D]}$ respectively. The intercepts and slopes of the regression lines from a plot of $\left[D_{0}\right]\left[A_{0}\right] / A_{\lambda}{ }^{[A: D]}$ against $1 /\left[D_{0}\right]$ were used to calculate the values of $E_{\lambda}[A: D]$ and $\mathrm{K}_{\mathrm{c}}^{[\mathrm{A}: D]}$ respectively. The data obtained for the stability constants at different temperatures were further utilized to calculate the standard enthalpy change $\left(\Delta H^{\circ}\right)$ using Eq 2.

$$
\log K_{\varepsilon}^{[A: D]}=\frac{\Delta H^{\circ}}{2.303 R T}+\text { constant }
$$

where $\mathrm{R}$ is the gas constant. The $\Delta H^{\circ}$ of the stavudine-chloranilic acid interaction was obtained from Eqn. 2 by plotting $\log \mathrm{K}_{\mathrm{c}}^{[\mathrm{AA:D}]}$ against the reciprocal of absolute temperature $T$, where it was calculated from the slope of the regression line.

Also Gibb's free energy $\left(\Delta G^{\circ}\right)$ and the entropy $\left(\Delta S^{\circ}\right)$ were calculated respectively from Eqn. 3 and Eqn. 4, and the results presented in Table 1.

$$
\begin{aligned}
\Delta G^{\circ} & =-R \operatorname{TIn} \mathrm{K}_{\mathrm{c}}^{[\mathrm{A}: \mathrm{D}]} \ldots \ldots \ldots \ldots \ldots \ldots . . \text { Eqn. } 3 \\
\Delta G^{o} & =\Delta H^{\circ}-\mathrm{T} \Delta S^{\circ} \ldots \ldots \ldots \ldots \ldots \ldots . \text { Eqn. } 4
\end{aligned}
$$

\section{Assay procedure for stavudine capsule}

Twenty stavudine capsules (Strides Arco Lab.) were emptied, thoroughly mixed by trituration in a mortar and an amount equivalent to $717.4 \mathrm{mg}$ of active drug was accurately weighed. This was mixed with methanol in a $100 \mathrm{ml}$ flask to extract the active drug. The mixture was filtered to remove the excipients after shaking for 30 min. The filtrate was thereafter made up to $100 \mathrm{ml}$ with methanol to provide a theoretical concentration of $3.2 \times 10^{-2} \mathrm{M}$ of stavudine solution. Serial volumes $(0.7,1.4,2.1,2.8$ and $3.5 \mathrm{ml}$ ) of the solution were transferred into different test tubes to give concentrations of $5,10,15,20$ and $25 \mathrm{mg}$ (as used in the Beer's plot), respectively. Sufficient methanol was added in each case to bring the volume to $4 \mathrm{ml}$. Chloranilic acid solution $\left(3.5 \times 10^{-3} \mathrm{M}\right.$, $1 \mathrm{ml}$ ) was then added in each case to bring the final volume to $5 \mathrm{ml}$ each. The contents were mixed, left for $1 \mathrm{~h}$ at room temperature and their absorbance determined at $526 \mathrm{~nm}$ against a blank of methanol and dioxan. The procedure was repeated five times. Percent recovery of stavudine from the dosage form was calculated by reference to its Beer's plot. This was repeated for the other brand of stavudine capsule (Melxicap).

\section{Statistical analysis}

The data obtained were analysed by SPSS version 11 and recorded as mean \pm standard deviation ( $S D, n=5)$. Statistically significant difference between brands of stavudine assayed by the proposed method was evaluated using the Students' t-test and oneway analysis of variance (ANOVA; Fischer LSD post-hoc test). Significant differences between means were considered at $p<0.05$.

\section{RESULTS}

\section{Absorption spectra}

A solution of chloranilic acid in 1, 4-dioxan produced a golden yellow colour with maximum wavelength of absorption at 457 $\mathrm{nm}$ (Fig 2). Instantaneous purple color was obtained on reaction of the yellow chloranilic acid solution with the solution of the stavudine in methanol.

The results show that the absorbance of the complex was high at zero time and increased slowly over the $200 \mathrm{~min}$ period of 
investigation (Fig. 3). The colour of the complex also remained stable after $24 \mathrm{~h}$.

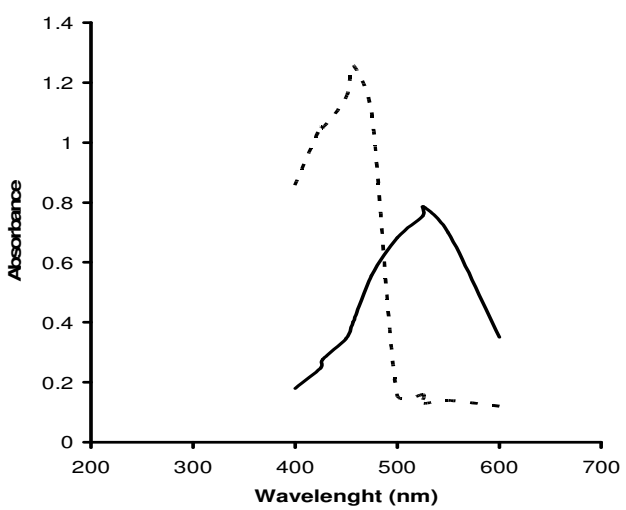

Figure 2: Absorption spectra of chloranilic acid (dotted line) and stavudine-chloranilic acid complex (continuous line)

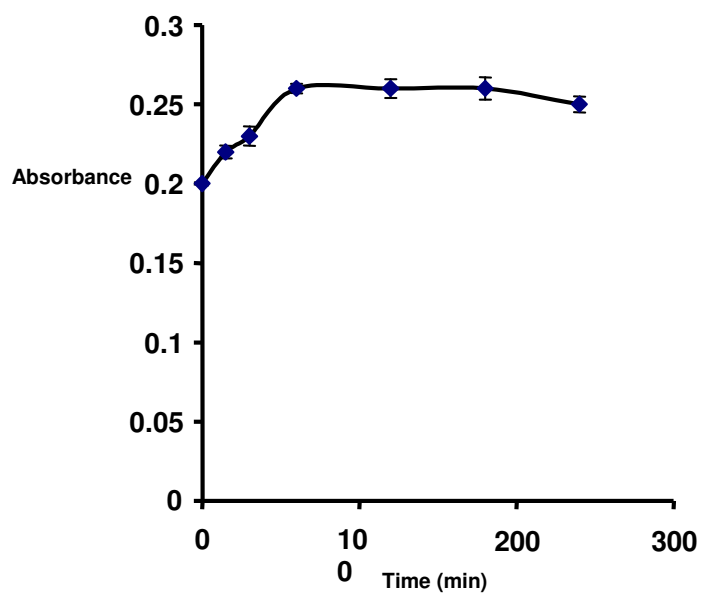

Figure 3: Time-absorbance relationship for stavudine-chloranilic acid complex

Beer's law was obeyed by the complex. At $526 \mathrm{~nm}$, a fairly linear relationship was obtained $\left(r^{2}=0.8469\right)$ between the absorbance and the concentration over the entire range studied $(5-40 \mathrm{mg} / 100 \mathrm{ml}$ of stavudine). The regression equation of the line, derived by the method of least squares, is as shown in Eq 5.

$$
A_{526 \mathrm{~nm}}=0.0259 \mathrm{C}+0.00
$$

where $\mathrm{C}$ is the concentration ( $\mathrm{mg} \%$ ) of stavudine-chloranilic acid complex. The correlation is fairly high.

\section{Job's plot for stavudine-chloranilic acid complex}

The stoichiometry of the stavudine-chloranilic acid complex was studied using Job's method of continuous variation. Its Job's plot for continuous variation is presented in Fig 4.

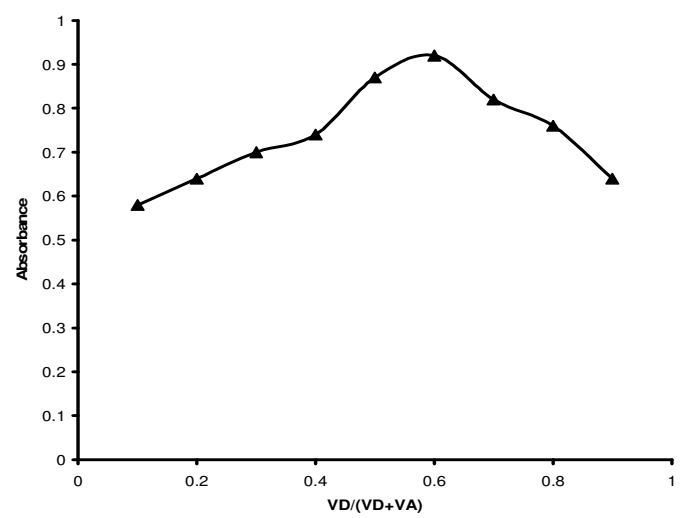

Figure 4: Job's plot of continuous variation for stavudine-chloranilic acid complex

\section{Stability constant, molar absorptivity and thermodynamic parameters}

The molar absorptivity, thermodynamic parameters and association constant for the stavudine-chloranilic acid complex were evaluated using the Benesi-Hildebrand equation (Eq 1) [13] and the data are shown in Table 1. The high negative $\Delta \mathrm{H}$ value (exothermic) of this complex suggests spontaneity of the complexation process. The entropy is high supporting the above assertion. The direct relationship between molar absorptivity and temperature indicates that the formed complex is strong and not dissociated easily even with increasing temperature.

\section{Recovery experiment}

The recovery results of stavudine from the dosage form using the proposed method 
Table 1: Thermodynamic parameters of the charge-transfer complex between stavudine and chloranilic acid

\begin{tabular}{lccccc}
\hline Temp $\left({ }^{\circ} \mathbf{C}\right)$ & $\begin{array}{c}\boldsymbol{K}_{c}^{[A: D]} \\
\left(\mathbf{m o l}^{-1)}\right)\end{array}$ & $\mathbf{\Delta G}^{\circ}(\mathbf{c a l} / \mathbf{m o l})$ & $\begin{array}{c}\Delta \boldsymbol{H}^{\circ} \\
(\mathbf{c a l} / \mathbf{m o l})\end{array}$ & $\begin{array}{c}\Delta \boldsymbol{S}^{\circ} \\
(\mathbf{c a l} / \mathbf{d e g} / \mathbf{m o l})\end{array}$ & $\begin{array}{r}\text { Molar absorptivity } \\
\times \mathbf{1 0}^{-10}\end{array}$ \\
\hline 30 & 244678.25 & -7470.19 & & & 67.11 \\
40 & 210172.34 & -7622.19 & -3778.96 & 11.62 & 77.52 \\
50 & 152322.92 & -7659.10 & & & 101.01 \\
60 & 127032 & -7776.09 & & & 123.46 \\
\hline
\end{tabular}

showed that recovery was $105.2 \pm 10.3$ and $122.8 \pm 6.03 \%(n=5)$ for stavudine from the two commercial products, unbranded and Melxicap ${ }^{\circledR}$, respectively. The recovery experiment on the standard stavudine solution gave a value of $99.85 \pm 1.95(n=5)$. These values were not statistically different $(p$ $<0.05)$.

\section{DISCUSSION}

The sharp change in colour from yellow in the chloranilic acid alone to purple in the complex with a bathochromic shift in absorption maxima (457 nm to $526 \mathrm{~nm}$ ) suggests a charge transfer complex formation (see Fig 2). In charge transfer complexation, the absorption maxima of the complexes formed are often shifted some nanometers to the longer wavelength side of the absorption band (bathochromic shift) of either of the components. This shift has been observed between chloranilic acid and other drugs [14]. The time - absorbance relationship of the complex suggests that the formation of the stavudine-chloranilic acid complex was instantaneous and the complex was stable for over $24 \mathrm{~h}$ with the purple colour still evident.

The complex obeyed Beer's law in the concentration range of $5-40 \mathrm{mg} \%$ with fair correlation. This conformity with Beer's law indicates that spectrophotometric analysis of electron donor-acceptor formation can be used for the quantitative analysis of stavudine. Interestingly, the correlation was fairly high indicating reliability. The stoichiometry, which was 2:1 (stavudine: chloranilic acid) for the complex, indicates the presence of two strong electron-accepting sites for chloranilic acid.

The stability constants presented were high and showed a reduction with increase in temperature. This is probably due to the dissociation of the complexes at higher temperatures [14]. It follows that although the complex can be regarded as thermostable, it, however, showed higher stability at lower temperature. The molar absorptivity values increased with increase in temperature; an interesting discovery which suggests that the complex was fairly strong enough to withstand elevated temperature conditions. Thus, with increase in temperature, dissociation of the complex was gradually activated leading to lower concentration of the complex in the reaction medium [14].

Free energy and the entropy changes showed negative and positive values, respectively. This indicates the spontaneity of the reaction. In fact, the instantaneous formation of the complex confirms this. High negative value of the standard enthalpy change $\left(\Delta H^{\circ}\right)$ together with association constant values indicate strong bonding between chloranilic acid and stavudine as well as high stability of the resultant chargetransfer complex.

In terms of the recovery, there was no statistically significant difference $(p<0.05)$ between the two brands (105.2 \pm 10.3 and $122.8 \pm 6.03)$. Although the results showed high quantitative recoveries, the standard deviation values were high suggesting that larger data may be used for validation of the proposed process. Thus, the proposed 
method gives very near values according to the label claims and further confirms a fair accuracy of the method. This result was not affected by the presence of excipients in the capsule since the excipients were removed before analysis. The proposed method is simple, low-cost and rapid compared to other analytical techniques used for the assay of stavudine..

\section{CONCLUSION}

Charge transfer complexation between stavudine and chloranilic acid occurred with a 2:1 stoichiometry, with maximum absorption at $526 \mathrm{~nm}$. Thermodynamically, the complex possessed high stability constant, and was still stable after $24 \mathrm{~h}$. This method was used to successfully assay stavudine in a tablet dosage forms. However, the precision and accuracy of the proposed method should be determined to enable an unbiased comparison with other analytical techniques in literature.

\section{ACKNOWLEDGMENT}

The authors are grateful to the Federal Medical Centre, Abakaliki, Nigeria, for providing the stavudine capsules free of charge as well as to Mrs Chisom Uzor for secretarial support.

\section{REFERENCES}

1. Foster $R$. Organic charge transfer complexes. London: Academic Press; 1969; $p 51$.

2. Hassib HB, Issa YM. Conductimetric studies of charge transfer complexes of some benzylidine aniline schiff's bases with substituted -benzoquinones. Egypt $J$ Anal Chem 1996; 39 (4): 329-338.

3. Basavaiah K, Charan VS. The use of chloranilic acid for the spectrophotometric determination of three antihistamines. Turk J Chem 2002; (26): 653-661.

4. Salem H. Analytical Study for the Charge-Transfer Complexes of Pregabalin. E-Journal of Chemistry 2009; 6(2): 332-340.

5. Shu EN, Muko KN, Ogbodo SO, Maduka IC, Ezeunala MN. Detection of quinolones on thin layer chromatographic plates using sigma- and pi-acceptors in 1, 4-dioxane. Biomed Res 2007; 18 (2): 135-138.

6. Adikwu MU, Ofokansi KC. Spectrophotometric determination of moclobemide by charge transfer complexation. J Pharm Biomed Anal 1997; 16: 527-532.

7. Ajali U. Spectrophotometric and thermodynamic parameters of albendazole-chloranilic acid complex in dioxan. Indian J Pharm Sci 2001; 63(2): 119-122.

8. Onunkwo GC, Adikwu MU. Quantitative reactions of two aminopenicillins with some acceptors. J West Africa Pharm 1991; (9):40-43.

9. Goodman L, Gillman A. The Pharmacological Basis of Therapeutics, $4^{\text {th }}$ Edition. New York: Macmillan; 1970; $p$ 1353-1360.

10. Anbazhagan S, Indumathy $N$, Shanmugapandiyan $P$, Sridhar SK. Simultaneous quantification of stavudine, lamivudine and nevirapine by UV spectroscopy, reverse phase HPLC and HPTLC in tablets. J Pharm Biomed Anal 2005; 39(3-4): 801-804.

11. Geffken D, Salem $H$. Spectrofluorimetric study of the charge-transfer complexation of certain fluoroquinolones with 2, 3, 5, 6-tetrafluoro- $p$ bezoquinone. Am J Appl Sci 2006; 3(8): 19521960

12. Job R. Advanced Physicochemical Experiments. London: Pitman, 1964; $p 54$.

13. Benesi HA, Hildebrand JH. Ultraviolet Absorption Bands of lodine and Aromatic Hydrocarbon. J Am Chem Soc 1949; 70: 2032-2033.

14. Attama AA, Nnamani PO, Agbo AN. Development of alternative assay technique for cephalexin by charge transfer interaction of the donor: acceptor type with chloranilic acid. Chinese Pharm J 2006; 58: 11-18. 